\title{
Geoscientists are not just rock stars
}

The geosciences are opening up to approaches that embrace multidisciplinary solutions to emerging and age-old problems. This should result in much interesting research, and challenges for scientists and funding agencies.

\section{Brendan Horton}

Billed as "The future of Earth sciences: the challenges and opportunities of multiple disciplines and diversity", the recent fiftieth anniversary of the American Geological Institute (AGI) in Washington, DC, was not only a birthday party, it was a chance to assess future needs and strategies. The need to make society aware of the importance of Earth science issues, and to pursue research that is relevant to society, were major themes of this one-day symposium. Other themes included multidisciplinary research, lateral thinking, and education and outreach.

Proponents of the multidisciplinary approach look set to get their opportunity to prove its value. Rita Colwell, director of the US National Science Foundation (NSF), recently called interdisciplinary research "nothing short of vital" and said she regarded this approach to science as "one of the major challenges for NSF in the coming years" (see Nature 396, 202; 1998).

For Mary Lou Zoback of the US Geological Survey, the grand challenge for the Earth sciences is to focus on themes rather than disciplines. She suggested several themes, including the need to recognize the signal of natural variability, to quantify the anthropogenic effect on climate and to look at the feedback loop between natural and perturbed systems. Zoback said a problembased structure was needed at NSF rather than one based on traditional disciplines. Colwell seems to agree, having described "departmental structure as a block" to multidiscipinary research. Zoback hopes that a theme-orientated structure will focus more on the Earth's surface, integrating the study of the bio-, litho-, atmo- and hydrospheres

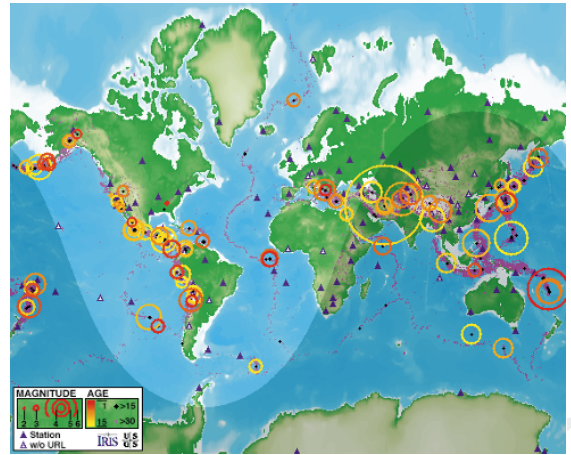

Shake, rattle and roll: IRIS's seismic monitor will be used in educational work (www.iris.edu).

to tackle today's most pressing problems.

Jonathan Price, state geologist for Neva$\mathrm{da}$, says multidisciplinary work has been going on for some time in the applied geosciences, and this does not mean simply bringing together people who study reflection seismology, stratigraphy and plate tectonics. Several years ago, the Nevada Bureau of Mines and Geology put together an earthquake emergency scenario. It included a lot of geology and seismology, said Price, but also had input from people with expertise in engineering geology, civil and structural engineering, emergency management, medicine, building inspection, law enforcement, and disaster relief, as well as businesspeople and government officials. Price emphasized that the skills of traditional Earth scientists will continue to be important and stated that "realizing what one's limitations are will become increasingly important as the field becomes more multidisciplinary".

It is not always true that multidisciplinary study means a group activity, according to Stephen Stanley, a professor of Earth and planetary sciences at Johns Hopkins University in Baltimore. His studies have taken him far afield into climatology, oceanography, physical anthropology, palaeontology, and other areas. He said: "I'm not an expert in all these fields, but I consult people who are and I know how to read. Exciting cross-disciplinary ideas entail connections, and a group of individuals lacks the neuronal connections of a single brain. There is often much to be gained, not by collaborating with others, but by collaborating with yourself."

Lateral thinking may mean different things in different sectors. To Donald Paul, vice-president of technical and environmental affairs at Chevron, it might mean applying geoscience to being a consulting specialist, a product developer, a systems integrator or a marketing manager. According to Thomas Hamilton, chairman, president and chief executive of EEX Corporation, these concepts mean being comfortable with several disciplines and learning the language of integrated solutions. In today's global village, understanding political science, diplomacy and culture can be more important to a project than a specific technology.

\section{Problem solving for the wholeEarth}

\section{Potter Wickware}

New tools and specialisms in the Earth sciences have emerged to help manage humanity's predicament with the environment and its resources. Global positioning satellites and satellite altimetry open up new ranges of observation of the Earth in space and time.

\section{Encouraging education and outreach initiatives}

The AGl anniversary was an occasion to encourage its members to get involved in education and outreach ( $E \& O)$, an area in need of attention in the geosciences. Wider exposure to Earth sciences should result from new US National Science

Education Standards, which place Earth sciences on a par with biology, chemistry and physics in kindergarten through to twelfthgrade education.

The importance of $E \& O$ is not lost on Michelle Hall-Wallace of the
University of Arizona and Katherine Johnson, director of E\&O at the Incorporated Research Institutions for Seismology (IRIS) in Washington, DC, both of whom are building programmes for educating non-specialists of all levels, with information and data available to the public (see Internet addresses).

Gregory van der Vink, director of planning at IRIS, has shown what can be done using public data in an educational setting. He and 12 students, from a class he teaches each fall atPrinceton
University's Science and Technology Council and Department of Geoscience, published a paper on the increasing economic vulnerability to natural disasters in the United States (Eos 79, 534-537; 1998). The paper was presented in Washington, DC, after which a congressman immediately offered any of the 12 students a congressional staff position, according to van der Vink. The course was developed not for producers of scientific information but for future consumers of that information in government or business.

\section{AGI's Earth Week} http://www.earthsciweek.org/ Michelle Hall-Wallace page http://geo.arizona.edu/ K-12/michellehall.html Incorporated Research Institutions for Seismology (IRIS) http://www.iris.washington.edu/ Princeton Earth Physics Project http://lasker.princeton.edu/ pepp.shtml 
Powerful modes of computer modelling allow experimental strategies involving large data sets to be devised and quickly refined. The Internet puts communities of scientists in instant communication with one another. Synchrotron radiation sources with powers many orders of magnitude greater than when X-rays were discovered allow views of unprecedented precision into materials.

Nevertheless, the problems of climate change, flooding, pollution and energy shortage are all too familiar in many parts of the world, while strategies for dealing with them often remain obscure. Research challenges at the most fundamental level await the efforts of geoscientists. For example, Miriam Kastner of the Scripps Institution of Oceanography in La Jolla, California, points out that we did not know of the existence of subsea vents until 1980. Since then we have discovered that the entire volume of the oceans cycles through them once every 5 million years, and through the subduction zones once every 200 million years.

"As we learn more about the interaction of the solid Earth and the hydrologic cycle we'll understand more about earthquakes, and possibly will be able to predict fine grain changes over time such as the Little Ice Age," she says. She adds that already we have found that some classic models of climate and geochemistry are wrong and must be revised. But this can only be done if scientists from disparate disciplines cooperate.

Geoscientists also have a vital contribution to make to human health in the area of environmental toxins and pollutants. There is an urgent need for more knowledge of dust particle size and chemistry, aerosol types, and the bioavailability of heavy metals, phosphate, arsenic and other substances. Here again, scientists must communicate not just across specialisms but across jurisdictions, because atmospheric pollutants are a global phenomenon. That the geoscience and medical communities have historically been disconnected from one another shows how "research is Balkanized," says Gordon Brown, of Stanford University's Synchrotron Radiation Laboratory. He suggests that perhaps the toxicologist is the logical interface through which this interaction will occur.

Charlie Alpers of the US Geological Survey in Sacramento, California, says that clear communication to outsiders about research problems and findings is also crucial. "We need to communicate clearly with the public, and persuade them and their representatives that what we are doing is worthwhile. Ultimately, public agencies and individual livelihoods depend on it." He says he will emphasize the human welfare aspect of what he does in a forthcoming short course in sulphate mineralogy, just as his agency accompanies many of the reports it publishes with clear fact sheets to make the work comprehensible to non-specialists, such as students.
Brown seconds this idea, saying that scientists ought to be able to make society care about their work. "Who cares about the distance between atoms?" he was recently asked by a political candidate in California. He gave an example of how the $0.4 \AA$ difference between the radii of $\mathrm{Cr}^{6+}$ and $\mathrm{Cr}^{3+}$ quite possibly allows the latter to mimic phosphate in life systems, with potentially lethal results. $\mathrm{He}$ added that it is important from a public health perspective to accurately characterize the bioavailability of different metals.

Although the interdisciplinary approach is mandatory for effective science and policy, it can take getting used to, admits Joe Smith, of the Department of Geophysical Sciences at the University of Chicago. Fifteen years ago the American Geophysical Union's public affairs committee asked him to organize a scientific session on the 'nuclear winter' issue. Once involved, he was appalled to learn of the magnitude of the problem that science had helped to create, and it was at this time that he began to alter his view of science and the responsibilities of the scientist.

Especially now, when the Earth sciences are expanding so greatly in concepts and information density, he believes it is important for the Earth scientist to "think out the interconnections between what he or she does and the various pieces of the tapestry of human life". Even though it may be easier to work on idealized problems, he has come to realize that members of the US National Academy of Sciences like himself have a duty to use their expertise for human welfare.

The cost of future research may be considerable by the historical standards of geoscience. For example, the current third generation of synchrotron radiation sources costs about \$15 million per cluster of experimental workstations, each of which should be manned by two dozen scientists and engineers, says Smith. Available funds are too

\section{Further information on geoscience careers}

GeoWeb Interactive: Jobs for

GeoScience/Engineering

http://www.ggrweb.com/job.htm |

\section{Earthworks}

http://ourworld.compuserve.com/ homepages/eworks/

\section{USGS Main homepage}

http://www.usgs.gov/

uSGS Mineral Resources

http://minerals.er.usgs.gov/

NAS Geosciences

http://www.nsf.gov/home/geo/start.htm

AGI Careers in Geosciences

http://www.agiweb.org/career/carehome.html

Graduate School and the Job Market

of the 1990s

http://www.agu.org/eos_elec/97117e.html

The Lamont-Doherty Earth Observatory

http://www.ldeo.columbia.edu/

The Columbia Earth Institute

http://www.earthinstitute.columbia.edu/

Alternative Careers in Science, edited by

Cynthia Robbins-Roth

http://www.amazon.com scanty to serve the growing number of environmental geoscientists who require data from these instruments.

As relative latecomers to the science funding competition, Earth scientists face a struggle to win adequate support. Smith is preparing a presentation to the National Academy of Sciences to raise $\$ 100$ million over five years to support staff at synchrotron radiation centres, with matching amounts to support research, teaching and public outreach at universities and experimental stations. He says this sum is a tiny fraction of the money spent on nuclear weapons management, and is in the range of the cheapest rocket mission to an asteroid.

Potter Wickware is a science writer in Oakland, California, USA.

e-mail:wickware@worldnet.att.net

\section{A risk proposition}

\section{Brendan Horton}

A geoscientist's career can veer off academic and government tracks into involvement in industry and even insurance. According to John Mutter, deputy director of Columbia University's Lamont-Doherty Earth Observatory, there are concerns to be aware of when too much of your funding comes from an industry-academic collaboration, especially for researchers intent on landing a rare academic post. But many scientists are diversifying their CVs to leave open employment options outside the academic world.

"More and more people are building in funding from the private sector," says Mutter, not only because it diversifies one's financial support, but also because people see the potential for a career in the private sector. While Lamont's partnerships have traditionally been dominated by the oil industry, "if we spoke two or three years from now, I'd [probably] be telling you about valuing climate information", says Mutter. With few exceptions, the industries most affected by climate have no research culture to enable them to understand it.

The winds of change that blew around Chris Barton, a research geologist with the US Geological Survey since 1985, may not have been hurricane force, but they were strong enough to make him a G. K. Gilbert Fellow at IBM with Benoit Mandelbrot, the 'father of fractals'. He followed this up with another fellowship at Lamont. These fellowships helped Barton's research to evolve from studying the physical phenomena of climate catastrophes to studying the magnitude of financial losses from these events, which in turn has affected the way reinsurance companies and the Federal Emergency Management Association evaluate risk. (Reinsurers insure major corporations and primary insurance providers.) 